\title{
LATVIAN CONSUMERS EATING MOTIVATIONS
}

\author{
Ilze Kalnina ${ }^{1}$, Evita Straumite ${ }^{1}$, Dace Klava ${ }^{1}$, Zanda Kruma ${ }^{1}$, Raquel P.F. Guine ${ }^{2}$ \\ 1*Department of Food Technology, Faculty of Food Technology, Latvia University of Agriculture, Jelgava LV-3001, Latvia, \\ e-mail:kalnina_ilze@yahoo.com \\ ${ }^{2}$ CI\&DET Research Centre, Polytecnic Institute of Viseu, Viseu, Portugal
}

\begin{abstract}
The society's dietary habits make an important impact on overall health status, the food that is consumed daily can be one of factors that prevent or, on the contrary, increase health risks. Eating habits, food choices, quantity and frequency of mealtimes are dependent on many variables from physiological to emotional needs. The aim of this research was to find out the factors that influence food choice of Latvian consumers.

The questionnaire was used as a basic tool for studies of Latvian consumers eating motivation, which was completed by 245 respondents $(75.1 \%$ female and $24.9 \%$ male) from different Latvia regions. The survey included ten parts - demographical information, anthropometric data and behavioural and health related elements, sources of information about healthy eating, factors related to food choices according to motivations (health aspect, emotional, economic, availability, social, cultural, environmental, political, marketing and commercials). The results of questionnaire show, that the $48 \%$ of respondents have motivation to eat healthy; Latvian consumers haven't united viewpoint regarding emotional motivations for eating $-33 \%$ agrees with this motivation form. Frequently physical exercises positively correlate with knowledge about healthy food, healthy motivations and also emotional motivations. More than half of respondents completely agree that food makes them feel good.
\end{abstract}

Keywords: eating motivation, survey, food choice

\section{Introduction}

It is well established that there are close interactions between eating habits and person's overall health condition. There have been studied numerous factors that predict unhealthy eating habits, however equally important is to understand aspects that promote healthy eating habits (Swan et al., 2015). To find out what impacts person's eating habits, there are proposed several scales and factors, e.g., four category model of motivations to eat - coping, social, compliance and pleasure (Jackson et al., 2003). In the different eating motivation survey results indicate 15 main factors that explains eating motivations - liking, habits, need and hunger, health, convenience, pleasure, traditional eating, natural concerns, sociability, price, visual appeal, weight control, affect regulation, social norms and social images (Renner et al., 2012), health and nutritional value, sensory appeal, familiarity and convenience, feeling good and safety, and natural content (Ares, Gambaro, 2007), set of individual level factors, socialenvironmental and physical-environmental factors (Swan et al., 2015), food liking, emotional coping, selfcontrol with food, costs and health issues may influence food choice (Dressler, Smith, 2013), taste, economy, convenience, health and variety are also widely described factors that determines food choices (Finkelstein et al., 2004), consumer individual attitudes, perceptions, usage of available resources should be also considered (Urala, Lähteenmäki, 2006). Through analysing all these factors, it is possible to find out causes of healthy and unhealthy eating, which is important to promote healthy eating of public, reduce obesity rates, encourage to consume healthier foods (Finkelstein et al., 2004), decrease rates of diseases like high blood pressure, diabetes, heart diseases (Miller, Cassady, 2012).

Eating is human physiological requirement to provide nutrients for adequate functioning of the human body and its growth. Beyond physiological demands for nutrition, psychological motivations also play important role for both healthy and disordered eating (Jackson et al., 2003). Due to increasing number of cases with eating disorders and obesity, there has been studied the role of emotions for development of these problems (Canetti et al., 2002). Emotions, state of mind and food choices can obviously interact with each other, where mood can affect food choice through physiological reactions that change desire for food or, on the contrary, food choice could make a change of mood (Gibson, 2006, Köster, Mojet, 2015). So, it works both ways - mood and emotions can alter food choice and food choice can change state of mind (Gibson, 2006). One of typical emotional states which makes a great impact on altering eating patterns is stress and stressful situations. Many studies are performed regarding stress induced eating changes but the results are contrary. Several studies indicate that restrained eaters under stress increase their amount of food intake more than non-restrained eaters (Zellner et al., 2006, Canetti et al., 2002), and that there are definitely changes in eating under stress, for emotional eaters it is overconsumption but for non-emotional eaters - both under and overconsumption in similar number of cases (Wallis, Hetherington, 2008).

As stated above, there are many psychological factors that make an important impact on consumers' food choice, these factors are possible to combine together and also analyse them separately. Some of aspects can promote eating disorders, weight gain and obesity that usually lead to different diseases and health problems, but some of them can boost healthy eating habits. As every person is individual, researching this topic is complex and must consist of different factors that interact with each other.

As previously declared, not only the emotions make the impact on food choices, social, cultural (Pliner, Mann, 2004), economic, environmental (Popkin et al., 2005), political, marketing and 
commercials issues also have essential meaning in defining person's eating habits. It is equally important to evaluate both healthy and unhealthy eating habits, in order to identify causes that promotes one and reduces the other (Williams et al., 2012). After summarising this kind of information it is possible to create recommendations for popularizing healthy nutrition. Also person's daily routine and eating routine should be considered in evaluation of eating habits (Jastran et al., 2009), although it is more helpful for individual improvement of healthy eating practises.

In order to change society's eating habits to healthier tendencies, it is critical to understand what factors influence food choices. The aim of this research was to find out the factors that influence food choice of Latvian consumers.

\section{Materials and Methods}

\section{Design of questionnaire}

Basic tool of study was questionnaire, which aimed to collect information about Latvian consumers eating motivations. The questionnaire was structured into different sections in order to gather information about respondents' lifestyle, knowledge about healthy eating, healthy and eating motivations.

The demographic information like age, gender, level of education, living environment and behavioural and health related elements like information about physical exercises, dietary regimes were addressed in the beginning of the questionnaire.

The questionnaire consisted from 29 questions (Table 1), which aimed to evaluate knowledge on three distinct areas: 10 questions for knowledge about healthy food, 9 questions for healthy motivation and 10 questions about emotional motivations.

Table 1

\section{Design of questionnaire}

\begin{tabular}{ll}
\hline Item & Complete question \\
\hline S1 & Knowledge about healthy food \\
S1.1. & A healthy diet is based on calorie count \\
S1.2. & We should never consume sugary products \\
S1.3. & Fruit and vegetables are key to being healthy \\
S1.4. & $\begin{array}{l}\text { A healthy diet should be balanced, varied and } \\
\text { complete }\end{array}$ \\
S1.5. & $\begin{array}{l}\text { We can eat everything, as long as it is in small } \\
\text { quantities }\end{array}$ \\
S1.6. & $\begin{array}{l}\text { I believe that a healthy diet is not cheap } \\
\text { S1.7. }\end{array}$ In my opinion it is strange that some people have \\
cravings for sweets
\end{tabular}

\begin{tabular}{ll}
\hline Item & Complete question \\
\hline S2.2. & It is important for me that my diet is low in fat \\
S2.3. & I always follow a healthy and balanced diet \\
S2.4. & It is important for me that my daily diet contains \\
a lot of vitamins and minerals \\
S2.5. & $\begin{array}{l}\text { I do not avoid foods, even if they may raise my } \\
\text { cholesterol }\end{array}$ \\
S2.6. & I try to eat foods that do not contain additives \\
S2.7. & I do not eat processed foods, because I do not \\
Snow what they contain
\end{tabular}

They are all presented in ordinal Likert scale, where respondents could measure each statement with their opinion - 1 - strongly disagree; 2 - disagree; 3 - neither agree nor disagree; 4 - agree and 5 - strongly agree, and additional option "no opinion".

\section{Selection of respondents}

The study was conducted with 245 respondents. The participation in the questionnaire was voluntary and the questionnaire was distributed using internet network (www.visidati.lv). The respondents were selected by convenience, although attempting to reach different parts of society, in terms of age, gender, education, living environment, civil state, professional activities.

\section{Statistical analysis}

The software SPSS, from IBM Inc. (version 24), was used for all data analysis. To validate questionnaire's results there was used Cronbach's alpha, the closer Cronbach's alpha coefficient is to 1.0 the greater the internal consistency of the items in the scale, general view for interpreting Cronbach's alpha is if $\alpha \geq 0.9$, then result is excellent, if $0.9>\alpha \geq 0.8$, then - good, if $0.8>\alpha \geq 0.7$, then - acceptable, of $0.7>\alpha \geq 0.6$, then questionable, if $0.6>\alpha \geq 0.5$, then - poor, and if $0.5>\alpha$, then - unacceptable. All obtained data were statistically processed using several descriptive statistics tools, there was determined significance of the test ( $\mathrm{p}$-value), where level of significance was 0.05 .

There were calculated mean, median for each subscale of questionnaire and, as subscales had normal 
distribution, there were also calculated Pearson correlation coefficients between different subscales.

\section{Results and Discussion}

The total number of respondents was 245 , from which $75.1 \%$ were female and $24.9 \%$ - male (Table 2), aged between 18 and 77 years, with an average age of 39.4 years.

Table 2

\begin{tabular}{|c|c|c|}
\hline \multicolumn{3}{|c|}{ Characterisation of respondents } \\
\hline Variable & $\begin{array}{l}\text { Number of } \\
\text { respondents }\end{array}$ & $\begin{array}{l}\text { Percentage, } \\
\%\end{array}$ \\
\hline $\begin{array}{l}\text { Gender } \\
\text { female } \\
\text { male }\end{array}$ & $\begin{array}{l}183 \\
61 \\
\end{array}$ & $\begin{array}{l}75.1 \\
24.9 \\
\end{array}$ \\
\hline $\begin{array}{l}\text { Living environment } \\
\text { rural } \\
\text { urban }\end{array}$ & $\begin{array}{l}50 \\
195 \\
\end{array}$ & $\begin{array}{l}20.4 \\
79.6\end{array}$ \\
\hline $\begin{array}{l}\text { Education } \\
\text { primary school } \\
\text { secondary school } \\
\text { university }\end{array}$ & $\begin{array}{l}2 \\
33 \\
210 \\
\end{array}$ & $\begin{array}{l}0.8 \\
13.5 \\
85.7 \\
\end{array}$ \\
\hline Practice any specific volunt & Iry dietary regil & \\
\hline raw foodism & 2 & 0.8 \\
\hline fruitarianism & - & - \\
\hline vegetarianism & 7 & 2.8 \\
\hline veganism & 1 & 0.4 \\
\hline flexitarianism & 7 & 2.8 \\
\hline $\begin{array}{l}\text { caloric restriction / weight } \\
\text { control }\end{array}$ & 25 & 10.2 \\
\hline religious restrictions & 5 & 2.0 \\
\hline general food regime & 198 & 80.9 \\
\hline $\begin{array}{l}\text { Physical exercise } \\
\text { never }\end{array}$ & 20 & 8.15 \\
\hline $\begin{array}{l}\text { sporadically (less than } 1 \\
\text { time a week) }\end{array}$ & 64 & 26.1 \\
\hline $\begin{array}{l}\text { occasionally ( } 1 \text { time a } \\
\text { week) }\end{array}$ & 84 & 34.3 \\
\hline $\begin{array}{l}\text { moderately ( } 2-3 \text { times a } \\
\text { week) }\end{array}$ & 57 & 23.3 \\
\hline $\begin{array}{l}\text { intensively ( more than } \\
3 \text { times a week) }\end{array}$ & 20 & 8.15 \\
\hline
\end{tabular}

More than half of all respondents $(80 \%)$ are in active working age (between 18 to 50 years), $18.0 \%$ - from 51 to 65 years, and $2.0 \%$ over 65 years. Most of respondents lived in an urban environment $(79.6 \%)$, while $20.4 \%$ lived in rural areas (Table 2). More than $80.0 \%$ of respondents have general food regime, but $19.1 \%$ practice some specific dietary regime (caloric restriction / weight control, vegetarianism, flexitarianism, religious restrictions and raw foodism). $65.7 \%$ of respondents at least once a week deals with the physical exercises (of which $8.1 \%$ more than three times a week), whereas for a balanced diet daily takes care $8.5 \%$ of respondents and $23.2 \%$ for a balanced diet think never, or very rarely.

There were calculated Cronbach's alpha for each subscale in order to check reliability of questionnaire. For subscale knowledge about healthy food it was 0.692 , for subscale healthy motivations -0.770 and for subscale emotional motivations -0.817 , but global Cronbach's alpha for these 3 subscales with
29 questions was 0.863 . It means that questionnaire results are very good in terms of reliability, as $0.8-0.9$ suggests high internal consistency.

The data shows that large part of respondents isn't concerned with balanced diet, but regularly makes physical exercises. The studies show that physical exercises alone aren't so effective, as combined with healthy diet for weight loss outcomes (Stephens et al., 2014). Also balanced diet and regular physical activities provides lasting, long-term success (Keller, Hartmann, 2016). Analysing total data for all three subscales (Figure 1), 44\% of respondents strongly agree and agree with statements regarding knowledge about healthy foods, $48 \%$ agrees with healthy motivations statements and $34 \%$ of respondents accepts emotional motivations statements.

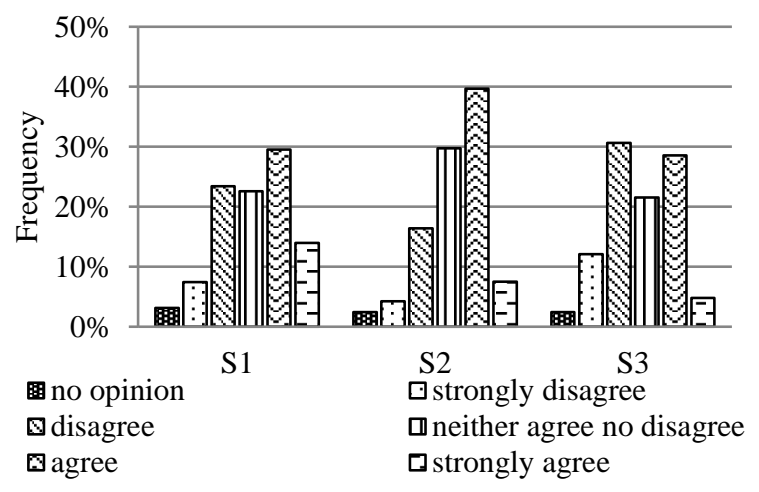

Figure 1. Level of knowledge about healthy diet, healthy and emotional motivations

The lowest agreement level is for the emotional subscale, other two scales positively reach almost half of all respondents.

If compare subscales between each other, it can be concluded that all have significant positive correlations (Table 3).

Table 3

Pearson correlation for the subscales

\begin{tabular}{lccc}
\hline Item & S1 & S2 & S3 \\
\hline S1 & 1.000 & $0.486^{*}$ & $0.475^{*}$ \\
S2 & $0.486^{*}$ & 1.000 & $0.365^{*}$ \\
S3 & $0.475^{*}$ & $0.365^{*}$ & 1.000 \\
\hline
\end{tabular}

* Correlation is significant at the 0.01 level (2-tailed)

Moderate, in this case more remarkable, positive correlations $(0.40>r>0.59)$ are between knowledge about healthy food and healthy motivations and emotional motivations. It means that if increases level of knowledge, then proportionally should increase levels of healthy and emotional motivations.

There was calculated correlation between subscales and other variables like gender and physical exercises of respondent.

There is significant, although relatively small, positive correlations between gender and healthy motivations. That is completely acceptable as females tend to be more demanding to healthiness of food. Physical exercises 
positively correlate with knowledge about healthy food, healthy motivations and also emotional motivations.

Questionnaire shows that $44 \%$ of respondents are well informed about what is healthy diet and what it should contain (Figure 2). And accordingly to that $48 \%$ of respondents have marked that they agree to healthy motivations.

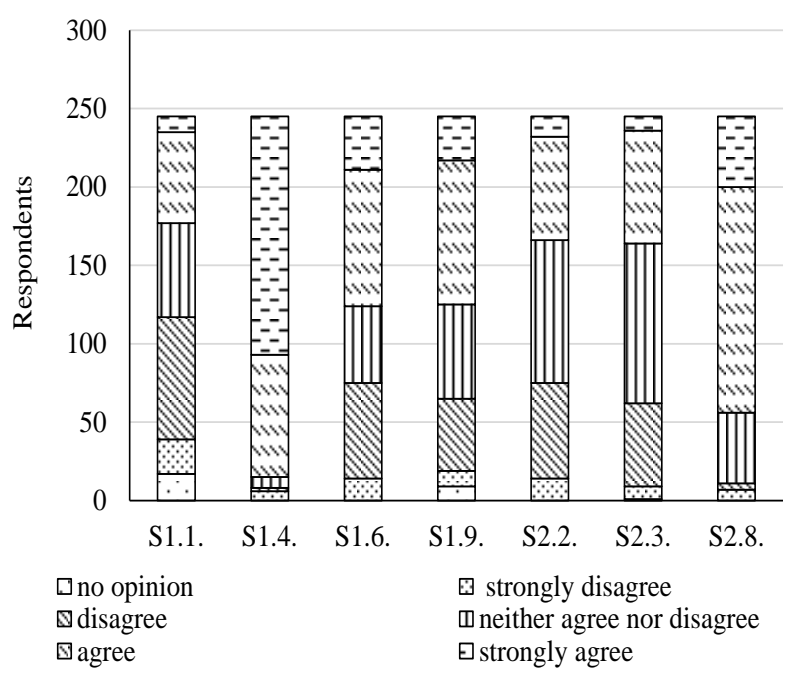

Figure 2. Level of Latvian knowledge and healthy eating motivations

Respondents who agree with the statement that calorie count is important, also agree that it is relevant that their diet is low in fat, questions about balanced diet (S1.4. and S2.3.) doesn't have similar proportion, almost all respondents have knowledge that healthy diet should be balanced, varied and complete, but only less than a half of them agrees that they follow healthy diet.

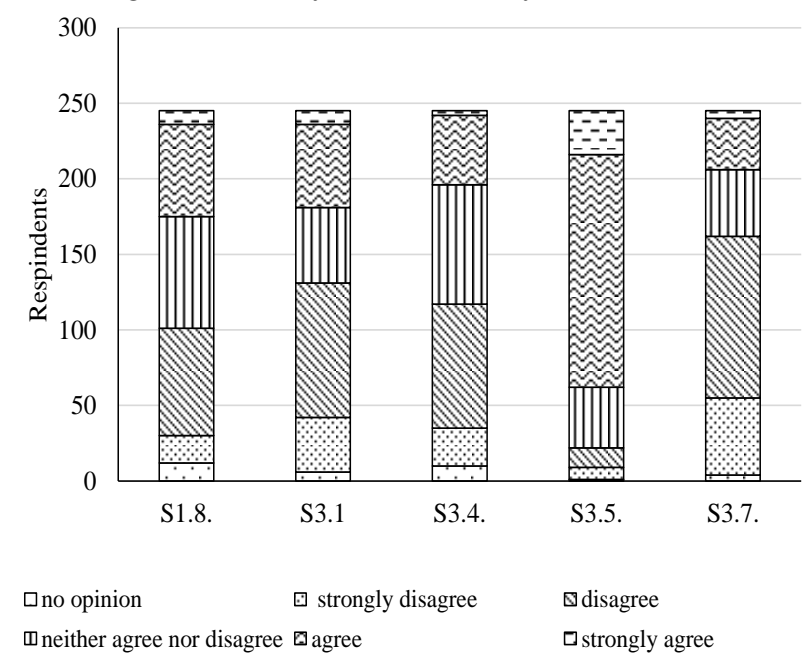

Figure 3. Level of knowledge and emotional motivations

Studies regarding this subject are contrary to questionnaire's results - it is establishes that knowledge about nutrition combined with socio-economic status improves diet quality (Beydoun, Wang, 2007) and it even significantly correlates with higher adherence to some diets (Bonaccio et al., 2013).
More than half of respondents completely agree that food makes them feel good (S.3.5.), smaller proportion, about $25 \%$ of respondents, is for similar statements that food helps cope with stress, helps relax and cope with life (Figure 3).

In the research obtained results corroborate with opinions of Torres and Nowson (2007), that in acute stress situations, there may be expected reduced food intake in short term, but in chronic stress situations more likely food intake will increase due to cortisol raise, and it can tempt person to consume hedonic, energy-dense foods.

Largest part of respondents disagrees that they should never consume sugary products and they also disagree opinion that is strange to have cravings for sweets. Similar opinion is also about question that there often are cravings for sweets when depressed, although here agrees only around half of respondents (Figure 4).

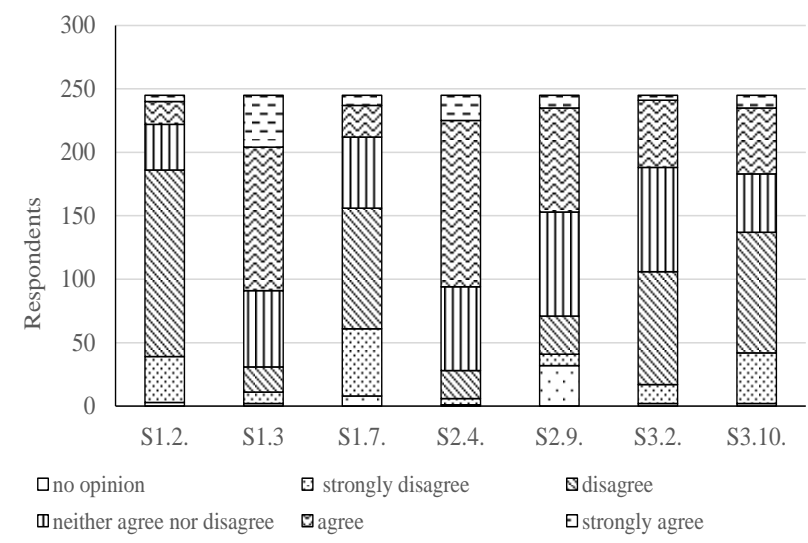

Figure 4. Level of knowledge, healthy and emotional motivations

Fruits and vegetables are highly recommended to consume in order to keep up healthy weight and decrease chronic disease risks, and social marketing campaigns, mass media and policy changes could help to improve community's consumption (Chapman et al., 2016). More than half of respondents have stated that fruits and vegetables are key to be healthy and they also agree with the statement that it is important that daily diet contains vitamins and minerals. The results of DíazGarcés et al. (2016) research show that persons with higher education level tend to increase amount of fruits and vegetables.

Obtained results (Table 5; S1.5.) indicate that 61.3\% Latvian respondents agree, that eat everything, as long as it is in small quantities, but $22.8 \%$ - neither agree nor disagree with this statement. For $46.3 \%$ respondents it is very important, that food what they eat is healthy. Regarding question S2.6., 58.1\% respondents (agree and strongly agree) try to eat food that does not contains additives.

Shim et al. (2011) present that consumers are concerned about artificial sweeteners, colorants and preservatives, and usually they lack information or it is insufficient about food additives, but the results of this questionnaire show that Latvian consumers have strong opinions regarding food additives and try to avoid them. 
Statistical regarding the relationship between knowledge about healthy eating, healthy and emotional motivations

\begin{tabular}{lllllllll}
\hline Item & \multicolumn{9}{c}{ Respondents answers, \% } & Mean & Std. Deviation \\
\cline { 2 - 7 } & $\begin{array}{l}\text { no } \\
\text { opinion } \\
(\mathbf{0})\end{array}$ & $\begin{array}{l}\text { strongly } \\
\text { disagree } \\
(\mathbf{1})\end{array}$ & $\begin{array}{l}\text { disagree } \\
(\mathbf{2})\end{array}$ & $\begin{array}{l}\text { neither } \\
\text { agree } \\
\text { disagree (3) }\end{array}$ & $\begin{array}{l}\text { agree (4) } \\
\text { (3) }\end{array}$ & $\begin{array}{l}\text { strongly } \\
\text { agree (5) }\end{array}$ & & \\
\hline S1.5. & 1.6 & 2.0 & 12.2 & 22.8 & 46.8 & 14.6 & 3.55 & 1.053 \\
S2.1. & 1.6 & 4.9 & 13.0 & 34.1 & 39.5 & 6.9 & 3.25 & 1.041 \\
S2.6. & 0.7 & 4.9 & 13.0 & 23.2 & 44.4 & 13.8 & 3.46 & 1.084 \\
S2.7. & 2.4 & 7.7 & 39.0 & 28.9 & 18.3 & 3.7 & 2.63 & 1.058 \\
S3.3. & 4.9 & 9.3 & 28.9 & 26.8 & 28.1 & 2.0 & 2.69 & 1.174 \\
S3.9. & 2.0 & 3.7 & 17.5 & 15.0 & 47.2 & 14.6 & 3.46 & 1.168 \\
\hline
\end{tabular}

Fifth part of respondents, when purchasing food, does not pay attention if there are added food additives in the product production process. Considering the responses "neither agree nor disagree" (Table 5; S3.3.), the 26.8\% respondents are not sure, that the reason for product choice is to keep them awake and provide alert.

\section{Conclusions}

$44 \%$ of respondents are well informed about what healthy diet is and what it should contain, and $48 \%-$ have marked that they agree to healthy motivations. More than half of respondents completely agree that food makes them feel good, but overall agreement of emotional motivations reach only $34 \%$ of respondents. Physical exercises positively correlate with knowledge about healthy food, healthy motivations and also emotional motivations.

Gender has significant, but weak, correlation with healthy motivations.

\section{Acknowledgment}

This research was prepared in the ambit of the multinational project from CI\&DETS Research Centre (IPV e Viseu, Portugal) with reference PROJ/CI\&DETS/2016/0008: EATMOT.

\section{References}

1. Ares G., Gambaro A. (2007) Influence of gender, age and motives underlying food choice on perceived healthiness and willingness to try functional foods. Appetite, Vol. 49, p. $148-158$.

2. Beydoun M.A., Wang Y. (2007) Do nutrition knowledge and beliefs modify the association of socio-economic factors and diet quality among US adults? Preventive Medicine, Vol. 46, p. 145-153.

3. Bonaccio M., Di Castelnuovo A., Costanzo S., De Lucia F., Olivieri M., Donati M.B., de Gaetano G., Iacoviello L., Bonanni A. (2013) Nutrition knowledge is associated with higher adherence to Mediterranean diet and lower prevalence of obesity. Results from the Molisani study. Appetite, Vol. 68, p. 139-146.

4. Canetti L., Bachar E., Berry E.M. (2002) Food and emotion. Behavioural Processes, Vol. 60, p. 157-164.
5. Chapman K., Havill M., Watson W.L., Wellard L., Hughes C., Bauman A., Allman-Farinelli M. (2016) Time to address continued poor vegetable intake in Australia for prevention of chronic disease. Appetite, Vol. 107, p. 295-302.

6. Díaz-Garcés F.A., Vargas-Matos I., Bernabé-Ortiz A., Diez-Canseco F., Trujillo A.J., Miranda J. J. (2016) Factors associated with consumption of fruits and vegetables among Community Kitchens customers in Lima, Peru. Preventive Medicine Reports, Vol.4, p. $469-473$

7. Dressler H., Smith C. (2013) Food choice, eating behavior, and food liking differs between lean/normal and overweight/obese, low-income women. Appetite, Vol. 65, p. $145-152$.

8. Finkelstein E., French S., Variyam J.N., Haines P.S. (2004) Pros and Cons of Proposed Interventions to Promote Healthy Eating. American Journal of Preventive Medicine, Vol. 27, p. 163-71.

9. Gibson L.E. (2006) Emotional influences on food choice: Sensory, physiological and psychological pathways. Physiology \& Behavior, Vol. 89, p. 53-61.

10. Jackson B., Cooper L.M., Mintz L., Albino A. (2003) Motivations to eat: Scale development and validation. Journal of Research in Personality, Vol. 37, p. 297-318.

11. Jastran M.M., Bisogni C.A., Sobal J., Blake C., Devine C.M. (2009) Eating routines. Embedded, value based, modifiable, and reflective. Appetite, Vol. 52, p. 127-136.

12. Keller C., Hartmann C. (2016) Not merely a question of self-control: The longitudinal effect of overeating behaviors, diet quality and physical activity on dieters' perceived diet success. Appetite, Vol. 107, p. 213-221.

13. Köster E.P., Mojet J. (2015) From mood to food and from food to mood: A psychological perspective on the measurement of food-related emotions in consumer research. Food Research International, Vol. 76, p. 180-191.

14. Pliner P., Mann N. (2004) Influence of social norms and palatability on amount consumed and food choice. Appetite, Vol. 42, p. 227-237.

15. Popkin M.B., Duffey K., Gordon-Larsen P. (2005) Environmental influences on food choice, physical activity and energy balance. Physiology \& Behavior, Vol. 86, p. 603-613.

16. Renner B., Sproesser G., Strohbach S., Schupp H.T. (2012) Why we eat what we eat. The eating motivations survey (TEMS). Appetite, Vol. 59, p. 117-128. 
17. Shim S., Seo S.H., Lee Y., Moon G., Kim M., Park J. (2011) Consumers' knowledge and safety perceptions of food additives: Evaluation on the effectiveness of transmitting information on preservatives. Food Control, Vol. 22, p. 1054-1060.

18. Miller L.M., Cassady D.L. (2012) Making healthy food choices using nutrition facts panels. The roles of knowledge, motivation, dietary modifications goals, and age. Appetite, Vol. 59, p. 129-139.

19. Stephens S.K., Cobiac L.J., Veerman J.L. (2014) Improving diet and physical activity to reduce population prevalence of overweight and obesity: An overview of current evidence. Preventive Medicine, Vol. 62, p. 167-178.

20. Swan E., Bouwman L., Hiddink G.J., Aarts N., Koelen M. (2015) Profiling healthy eaters. Determining factors that predict healthy eating practices amon Dutch adults. Appetite, Vol. 89, p. 122-130.
21. Torres J.S., Nowson A.C. (2007) Relationship between stress, eating behaviour, and obesity. Nutrition, Vol. 23, p. 887-894.

22. Urala N., Lähteenmäki L. (2006) Hedonic ratings and perceived healthiness in experimental functional food choices. Appetite, Vol. 47, p. 302-314.

23. Wallis D.J., Hetheringotn M.M. (2008) Emotions and eating. Self-reported and experimentally induced changes in food intake under stress. Appetite, Vol. 52, p. 355-362.

24. Williams L.K., Thornton L., Crawford D. (2012) Optimising women's diets. An examination of factors that promote healthy eating and reduce the likelihood of unhealthy eating. Appetite, Vol. 59, p. 41-46.

25. Zellner D.A., Loaiza S., Gonzalez Z., Pita J., Morales J., Pecora D., Wolf A. (2006) Food selection changes under stress. Psysiology \& Behavior, Vol. 87, p. 789-793. 